\title{
Comparison of two oxygen conserving nasal prong systems and the effects of nose
} and mouth breathing

\author{
G A GOULD, I S FORSYTH, D C FLENLEY \\ From the Rayne Laboratory, Department of Respiratory Medicine, City Hospital, Edinburgh
}

Long term domiciliary oxygen treatment prolongs survival in patients with hypoxic chronic bronchitis and emphysema ${ }^{12}$ but is expensive. ${ }^{3} \mathrm{~A}$ recently developed nasal prong system incorporating a pendant reservoir ("Oxymizer Pendant," Chad Therapeutics Inc, Woodland Hills, California) stores oxygen during expiration and delivers it as a bolus at the onset of the next inspiration. We have compared the oxygen conserving ability of this device with standard nasal prongs and with a commercial system with a moustache reservoir ("Oxymizer," Chad Therapeutics). We have also measured the effect of mouth and nose breathing on oxygen delivery by these devices.

\section{Patients and methods}

We studied 12 patients (seven men and five women, aged 44-76 years) with hypoxic chronic bronchitis and emphysema who were in a stable condition $\left(\mathrm{FEV}_{1} \mathbf{0} 2-1.21\right.$; FVC 0.8-3.8 l; arterial oxygen tension $\left(\mathrm{PaO}_{2}\right)$ 5.4-8.7 kPa; arterial carbon dioxide tension $\left(\mathrm{PaCO}_{2}\right)$ 5.3-7.4 kPa). Arterial oxygen saturation $\left(\mathrm{SaO}_{2}\right)$ was measured by HewlettPackard 47201A ear oximeter, and oxygen was delivered by a calibrated rotameter measuring to $0.051 \mathrm{~min}^{-1}$ (AP6222 flow meter, Rotameter Manufacturing Co Ltd).

\section{STUDY 1}

Each patient breathed oxygen for two periods in random order, with the pendant or with nasal prongs, oxygen being delivered at flow rates of $0.5,1.0,1.5,2.0$, and $3.01 \mathrm{~min}^{-1}$, with stepwise increases. Oxygen was continued until $\mathrm{SaO}_{2}$ was stable at each flow rate and the flow was then increased to the next level. A stable baseline $\mathrm{SaO}_{2}$ was recorded when the patient had been breathing room air for at least 20 minutes before each period of oxygen delivery.

\section{STUDY 2}

In 11 patients we assessed the effect of nose and of mouth breathing on oxygen delivery by nasal prongs and by the pendant and moustache devices. Oxygen was delivered for two separate periods, one during breathing through the nose (mouth closed) and one during breathing with the mouth open. When a stable baseline $\mathrm{SaO}_{2}$ had been recorded with the patient breathing room air, oxygen was delivered at flows of 1.0 and then $2.01 \mathrm{~min}^{-1}$, each rate being continued until $\mathrm{SaO}_{2}$ was stable. Between each oxygen breathing period

Address for reprint requests: Dr GA Gould, Rayne Laboratory, Department of Respiratory Medicine, City Hospital, Edinburgh EH10 SSB.

Accepted 5 February 1986 a stable baseline $\mathrm{SaO}_{2}$ with the patient breathing room air was recorded. The order of use of the devices and the nose and mouth breathing periods were assigned randomly.

Statistical comparisons were made by means of Wilcoxon's signed rank test for pair differences and analysis of variance.

\section{Results}

Study 1: Pendant versus nasal prongs The mean $\mathrm{SaO}_{2}$ when the patient was breathing room air was not significantly? different for the two devices $(85.7 \%$ prongs, $85.2 \%$ pendant), but at oxygen flow rates of $0.5,1.0,1.5,2.0$ and $3.0 \Gamma$ min $^{-1}$ the mean $\mathrm{SaO}_{2}$ values (\%) achieved with nasal prongso were $88 \cdot 4,90 \cdot 7,92 \cdot 0,93 \cdot 3$, and $94 \cdot 4$, and with the pendanfo $91 \cdot 2,93 \cdot 0,93 \cdot 8,94 \cdot 6$, and $95 \cdot 5$. Thus $33-50 \%$ less oxygen was required to achieve a given level of $\mathrm{SaO}_{2}$ with theo pendant than with standard nasal prongs.

Study 2: Pendant versus nasal prongs versus moustache reser voir and nose breathing versus mouth breathing The mear (SD) $\mathrm{SaO}_{2}$ for all three devices (table) shows that whether the patient was breathing through the mouth or through the nose both the pendant and the moustache device achieved significantly higher levels of $\mathrm{SaO}_{2}$ at both flow rates of oxy gen than did the standard nasal prongs. The $\mathrm{SaO}_{2}$ levels achieved by the pendant and by the moustache device weref not significantly different at any flow rate, and mouth anc nose breathing had no significant effect on the efficiency of these devices.

\section{Discussion}

A device that stores some of the oxygen expired and delivers it as a bolus during the first part of inspiration, when it is most likely to reach the alveoli, should conserve oxygenp yet still raise the patient's $\mathrm{SaO}_{2}$. Previous studies of the moustache device ${ }^{5}$ and of the pendant device ${ }^{6}$ showed an significant saving of oxygen, which was most evident at low oxygen flows. Owing to the shape of the dissociation curve however, a similar rise in alveolar $\mathrm{Po}_{2}$ at higher oxygen flow rates will have less effect on $\mathrm{SaO}_{2}$. High flow rates (when the reservoir contributes only a small fraction of the total gas delivered) or very low flow rates, which may not allow the reservoir to fill with each breath, will both reduce thes efficiency of the reservoir device. At flow rates of 0.5-3.0 T $\min ^{-1}$, however, these devices are significantly more efficient than standard nasal prongs. ${ }^{4-6}$ We previously showed tha? the efficiency of the moustache device varied from patient t@ patient. ${ }^{5}$ We therefore investigated the effect of nose versus mouth breathing in the same subjects as this may vary between different patients, and indeed probably within the 
Arterial oxygen saturation $\left(\mathrm{SaO}_{2}\right)$ (mean $(\mathrm{SD}), \%$ ) during mouth and nose breathing at different oxygen flows in 11 patients

\begin{tabular}{|c|c|c|c|c|c|}
\hline & \multirow[t]{2}{*}{ Baseline, room air } & \multicolumn{2}{|c|}{ Mouth breathing } & \multicolumn{2}{|c|}{ Nose breathing } \\
\hline & & $l / \min ^{-1}$ & $2 l \min ^{-1}$ & $1 / \min ^{-1}$ & $2 l \min ^{-1}$ \\
\hline $\begin{array}{l}\text { Nasal prongs } \\
\text { Pendant } \\
\text { Moustache }\end{array}$ & $\begin{array}{l}87 \cdot 5(3 \cdot 6) \\
88 \cdot 1(3 \cdot 6) \\
87 \cdot 8(3 \cdot 2)\end{array}$ & $\begin{array}{l}91 \cdot 3(3.0) \\
93 \cdot 1(2.9) \\
92 \cdot 8(2.5)\end{array}$ & $\begin{array}{l}93 \cdot 3(2 \cdot 2) \\
94 \cdot 5(2 \cdot 2) \\
94 \cdot 3(1 \cdot 8)\end{array}$ & $\begin{array}{l}90.7(2.5) \\
94.2(1.7) \\
92.9(2.6)\end{array}$ & $\begin{array}{l}93.5(2 \cdot 1) \\
95 \cdot 2(1.8) \\
94.7(1.8)\end{array}$ \\
\hline
\end{tabular}

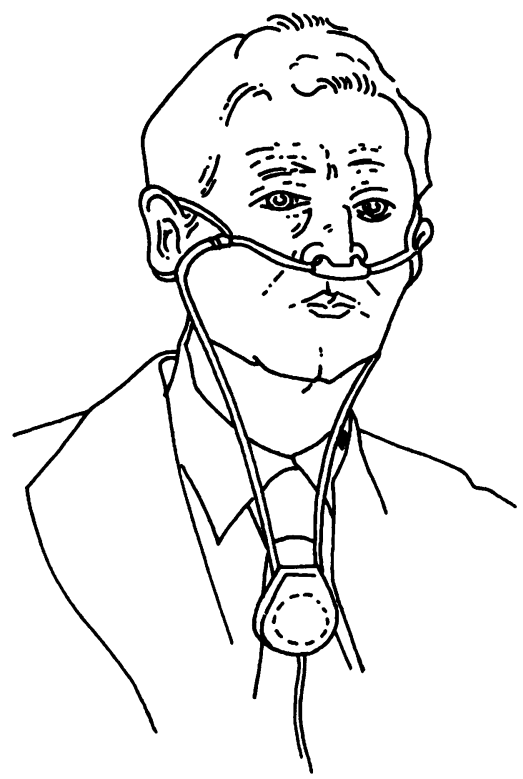

Pendant device in use.

same patient ${ }^{7}$; the results showed no difference in efficiency of oxygenation related to the breathing route.

In summary, we have shown that the pendant device is significantly more efficient than standard nasal prongs and achieves an equivalent $\mathrm{SaO}_{2}$ at a 33-50\% lower flow rate of oxygen. The oxygen saving ability is similar to that of the moustache reservoir, but the pendant was more acceptable as it can be disguised under clothing. We also found that even when patients were instructed to breathe only through the mouth both devices still achieved significant savings of oxygen. In practice, these oxygen saving devices will have their major role when oxygen is supplied from cylinders or liquid systems, where costs depend heavily on the flow rate of oxygen. This is less important with oxygen concentrators, but may become important if smaller concentrators are developed, for either portable use or use away from mains electricity supplies.

\section{References}

1 Nocturnal Oxygen Therapy Trial Group. Continuous or nocturnal oxygen therapy in hypoxaemic chronic obstructive lung disease: a clinical trial. Ann Intern Med 1980;93:391-8.

2 Medical Research Council Working Party. Long term domiciliary oxygen therapy in chronic hypoxic cor pulmonale complicating chronic bronchitis and emphysema. Lancet 1981;i:681-6.

3 Department of Health and Social Security. Report No 4/9/176. London: DHHS, December 1983.

4 Tiep BL, Nicotra B, Carter R, Belman MJ, Mittman C. Evaluation of a low flow oxygen-conserving nasal cannula. Am Rev Respir Dis 1984;130:500-2.

5 Gould GA, Hayhurst MD, Scott W, Flenley DC. Clinical assessment of oxygen conserving devices in chronic bronchitis and emphysema. Thorax 1985;40:820-4.

6 Tiep BL, Belman MJ, Mittmann C, Phillips R, Otsap B. A new pendant storage oxygen-conserving nasal cannula. Chest 1985;87:381-3.

7 Rodenstein DO, Stanescu DC. Soft palate and oronasal breathing in humans. J Appl Physiol 1984;57:651-7. 